Thorax (1976), 31, 101.

\title{
Miliary tuberculosis following homograft valve replacement
}

\author{
C. H. A N Y A N U ${ }^{1}, E$. NAS SA U, and M. Y A C O U B \\ Cardiothoracic Surgical Unit and Department of Pathology, \\ Harefield Hospital, Harefield, Middlesex
}

\begin{abstract}
Anyanwu, C. H., Nassau, E., and Yacoub, M. (1976). Thorax, 31, 101-106. Miliary tuberculosis following homograft valve replacement. Postoperative septicaemia with infective endocarditis is a recognized complication of open-heart surgery, in particular homograft or prosthetic replacement of cardiac valves. Several infective organisms, both bacterial and fungal, have been incriminated but infection due to tubercle bacilli has not, to our knowledge, been reported. The clinicopathological features of this condition are discussed.

During a five-year period, over 800 homograft replacements in the aortic and/or mitral positions have been performed at Harefield Hospital. Seven cases of miliary tuberculosis following homograft valve replacement are described here. In three, there was a past history suggestive of tuberculous infection but necropsy failed to reveal any caseous or other tuberculous lesion apart from recent miliary tuberculosis.

Vegetations on the homograft valves contained microcolonies of acid-fast bacilli in most cases. Tubercle bacilli of the human type were recovered by culture or guinea-pig inoculation in six of the seven cases, and in three the diagnosis was established during life; two of these survived on antituberculosis chemotherapy. The onset of symptoms varied from a few weeks to 12 months after operation. The main presenting symptom was intermittent pyrexia. In two patients the diagnosis was made on radiological and clinical grounds and in both, tubercle bacilli were grown from drill biopsy specimens of lung tissue.

The source of infection was presumed to be the homograft valves contaminated in the postmortem room. The antibiotic mixture used in the sterilization of the homografts was not effective against tubercle bacilli.
\end{abstract}

Total replacement of human cardiac valves with allografts has become established as a feasible and satisfactory method of treatment of some diseased and malfunctioning heart valves (Barratt-Boyes, and Roche, 1969; Gonzales-Lavin, Al-Janabi, and Ross, 1972; Yacoub, Towers, and Somerville, 1972.

Valve homografts have also been used successfully for reconstructive procedures in some congenital abnormalities such as right ventricular outflow tract obstruction. One of the complications of homograft valve replacement is infective endocarditis (Barnes et al., 1970; Grehl, Cohn, and Angell, 1972). The infective organisms could originate from the valve homograft or from other

Present address: Department of Surgery, University of Nigeria Teaching Hospital, Enugu, Nigeria sources, whatever method of sterilization is employed in the preparation of such homografts.

During the five years from August 1969, over 800 homograft valve replacements in the aortic and/or mitral positions have been performed at Harefield Hospital, and in that period seven cases of miliary tuberculosis following homograft valve replacement have been encountered. To our knowledge, no previous observation of miliary tuberculosis following homograft valve replacement has been reported. We feel that our patients present features of clinicopathological interest, especially to centres where human valve homografts are used.

\section{CASE REPORTS}

CASE 1 A 43-year-old housewife had a history of 
rheumatic fever and removal of a cervical gland at the age of 10 years. She presented with severe aortic and moderate mitral incompetence. Aortic homografts were inserted in the aortic and mitral positions in February 1970. The homograft in the aortic position had been obtained three days previously from a donor whose age and cause of death were not recorded. The other was obtained the day before insertion from a 68-year-old man who died of bronchopneumonia.

Pyrexia in the third postoperative week raised the suspicion of infective endocarditis and although several blood cultures were negative she was treated for six weeks with antibiotics. There was some improvement and she was discharged home. However, two weeks later she was readmitted with pyrexia, rigors, and headache. There was a right-sided pleural effusion. Septicaemia, subphrenic abscess, and fungal endocarditis were in turn suspected and treated (allergen not proved). She died in July 1970, 23 weeks after operation.

Necropsy revealed a small aneurysmal pocket under the non-coronary cusp of the homograft aortic valve. There was also a small vegetation between that cusp and the left coronary cusp and there were some vegetations on the mitral homograft and on the wall of the left atrium. Both valves appeared functionally good. There was no gross infection anywhere in the chest. Histological examination revealed miliary tubercles containing scanty acid-fast bacilli in the lungs, liver, spleen, kidneys, and suprarenals. About 15 hilar and mediastinal lymph nodes examined showed scanty miliary tubercles only. The vegetation under the left coronary cusp and on the mitral homograft showed microcolonies of acid-fast bacilli. Blood cultures taken five and 10 days before death and still kept in the incubator were centrifuged and the deposits were inoculated into guinea-pigs. The animals developed tuberculosis, and human type Mycobacterium tuberculosis sensitive to all antituberculosis drugs was recovered on culture of the animal spleens.

CASE 2 A 65-year-old housewife had a previous history of pneumonia in 1931, a tuberculous spine in 1932, and a psoas abscess in 1937. There was a four years' history of progressive dyspnoea and worsening effort tolerance causing severe incapacity. Calcific mitral valve disease with pulmonary hypertension was diagnosed.

At operation on 8 December 1970, a calcified stenotic and incompetent mitral valve was replaced by an aortic homograft obtained four days previously from a 60-year-old man who died of coronary thrombosis. She was readmitted to 흘 hospital on 14 December 1971 with pyrexia, $\frac{\bar{\sigma}}{\circ}$ dyspnoea, and confusion. Several blood cultures $\stackrel{\complement}{\complement}$ were negative. A chest radiograph suggested \% bronchopneumonia. After some early improve- $\overrightarrow{0}$ ment she died on the fifth day after readmission.

Necropsy revealed a shrunken bronchiectatic $\vec{\omega}$ right lower lobe and patchy bronchopneumonia in $\stackrel{\rho}{\circ}$ both lungs with marked emphysema. The myocar- $\vec{x}$ dium was flabby, and the homograft valve appeared functionally good. No cerebral lesion was $\overrightarrow{-}$ found. Histological examination revealed miliary $\vec{\circ}$ tubercles with scanty acid-fast bacilli in the lungs, liver, spleen, and kidneys.

CASE 3 A 59-year-old housewife had had chorea in childhood. There was a two years' history of progressive breathlessness, and atrial fibrillation had been present for 18 months. Right brachial $\vec{\oplus}$ embolism had responded to anticoagulant treat- $\vec{\varphi}$ ment. On admission mitral incompetence was diagnosed and on 29 November 1971 the mitral valve was replaced by an aortic homograft procured seven days previously from a 66-year-old man who died of diabetes mellitus. Postoperative progress was uneventful.

She was readmitted to hospital on 23 August $\stackrel{2}{\vec{P}}$ 1972 (about 9 months after operation) with diarrhoea, lethargy, and anorexia. There was no pyrexia nor dyspnoea. A soft apical systolic murmur and an easily palpable liver were noted. $A$ few days later evidence of heart failure and intermittent pyrexia developed and persisted. Exten- $\underset{x}{x}$ sive laboratory investigations were all negative. $\dot{\sigma}$ Treatment with antibiotics produced little improvement. A chest radiograph at this stage $\delta$ showed some right lower lobe consolidation, and raised the suspicion of tuberculosis. The patient $ᄋ$ died nine days after receiving antituberculosis chemotherapy (52 weeks after operation and 12 을 weeks after the onset of symptoms).

Necropsy revealed fresh and older organizing $N$ infarcts in the right lung and in the left lower $N$ lobe. There were vegetations on the aortic valve and also on the upper surface of the homograft valve. Histological examination of the lungs 0 showed, in addition to patchy bronchopneumonia and partly organized emboli, scattered miliary tubercles with very scanty acid-fast bacilli. Sec- 0 tions of the liver and the kidneys revealed scattered miliary tubercles. The vegetations from the $\mathbb{\mathbb { D }}$ homograft valve revealed small colonies of acid- $\mathbb{D}$ fast bacilli. Culture of the spleen grew Myco. tuberculosis sensitive to all antituberculosis drugs. 
Several blood cultures (still available after death) were negative on animal inoculation.

CASE 4 A 47-year-old housewife had a history of rheumatic fever aged 20 , and atrial fibrillation aged 24. A mitral valvotomy was performed in 1954. From 1964 she developed progressive features of restenosis of the mitral valve.

On 20 March 1972 the stenotic, incompetent, and torn mitral valve was replaced by an aortic homograft obtained two weeks previously from a man aged 66 years, who died of chronic bronchitis. Postoperative progress and follow-up at three months was satisfactory.

The patient was readmitted to hospital on 8 June 1972 with lethargy, drowsiness, jaundice, and an enlarged liver and spleen. There was no pyrexia and no significant abnormal cardiovascular signs. Liver function tests suggested cellular and obstructive hepatic damage. Blood cultures were sterile after 48 hours' incubation. She died two days after readmission.

Only a limited necropsy could be carried out. Histological examination revealed miliary tubercles with acid-fast bacilli in the liver and scanty acid-fast bacilli in a vegetation from the homograft valve. Later, human type Myco. tuberculosis, sensitive to all antituberculosis drugs, was cultured from the blood cultures taken on readmission (one week before death).

CASE 5 A 19-year-old Egyptian youth had had rheumatic heart disease since childhood. He was admitted with increasing breathlessness and paroxysmal nocturnal dyspnoea. Examination revealed severe mixed aortic valve disease. A chest radiograph showed cardiomegaly and clear lung fields. The aortic valve was replaced on 31 August 1973 with a homograft from a 60-year-old man who had died of coronary thrombosis two days previously. Postoperative progress was slow. A subsequent febrile illness was treated at another hospital with antibiotics, and the pyrexia apparently subsided. However, he had to be readmitted on 5 October 1973 (five weeks after operation) with pyrexia, dyspnoea at rest, dehydration, and peripheral oedema. He looked very ill; the liver was enlarged and tender. There were bilateral basal rales and a mild aortic ejection murmur. A chest radiograph at this time showed some bilateral congestion. Postoperative endocarditis was suspected but extensive laboratory investigations all proved negative. Another chest radiograph on 11 October 1973 showed widespread mottling and discrete lesions, particularly in the upper lobes. A high-speed drill biopsy of the left lung was carried out the same day and histological examination of the biopsy specimen showed tuberculosis. Myco. tuberculosis, sensitive to all antituberculosis drugs, was grown on culture of part of the specimen. Antituberculosis chemotherapy was started immediately. Signs of meningism then appeared. Lumbar puncture yielded turbid cerebrospinal fluid under increased pressure. Intrathecal streptomycin and hydrocortisone treatment was started. The patient gradually improved; the pyrexia and meningeal irritation subsided and he was gradually mobilized. On 16 November 1973 (77 days after operation) he was found unconscious. All attempts at resuscitation failed.

Findings at necropsy included some organizing exudate but no acid-fast bacilli in the basal cistern of the brain. Gross oedema and confluent cellular miliary tubercles with scanty acid-fast bacilli were seen in the lungs, and miliary tubercles were found in the other organs. About 24 sections of mediastinal, hilar, and carinal lymph nodes were examined and showed, with few exceptions, miliary tubercles with scanty acid-fast bacilli. Blood cultures taken between 11 days and one day before death grew Myco. tuberculosis sensitive to all antituberculosis drugs. Tubercle bacilli were also grown from a urine specimen taken at the time of the lung biopsy.

CASE 6 A 64-year-old man was hospitalized in May 1973 with Streptococcus viridans endocarditis of the aortic valve. He improved sufficiently after eight weeks' penicillin treatment to be discharged. He was readmitted to the same hospital later in congestive heart failure which responded to medical treatment. When seen at Harefield in August 1973 he had signs of severe aortic incompetence. On 31 August 1973 the diseased aortic valve, showing two large perforations, was replaced by a homograft obtained two days previously from a 66-year-old woman who died of cerebral haemorrhage.

Early pyrexia in the postoperative period settled spontaneously and he was discharged in a satisfactory clinical condition. About six weeks after operation he was admitted to another hospital with pyrexia, rigors, and night sweats. When transferred to our unit three days later he was afebrile but rigors and night sweats persisted. A radiograph showed clear lung fields. No organisms were isolated from 25 blood cultures taken within 10 days, nor did other investigations show evidence of systemic infection. However, a 
radiograph taken on 29 October 1973 (61 days after operation) revealed widespread miliary opacities in the lungs. A high-speed drill biopsy of the lung taken at this time showed tubercles on histological examination. Later Myco. tuberculosis, sensitive to all antituberculosis drugs, was grown on culture of part of the specimen. Antituberculosis chemotherapy was started immediately. The patient responded well to this and was discharged six weeks later. $\mathrm{He}$ has remained haemodynamically and radiologically in a satisfactory condition.

CASE 7 A 70-year-old housewife presented with signs of severe mitral incompetence. There was no history of tuberculosis. A chest radiograph showed calcified foci in both lungs and in the hilar and paratracheal glands. At operation on 11 March 1971 a floppy mitral valve with ruptured chordae tendineae (McKay and Yacoub, 1973) was found and replaced by an inverted aortic homograft obtained six days earlier from a 59year-old man who died of coronary thrombosis.

In early 1972 (about 11 months after the operation) the patient was admitted to another hospital with malaise, intermittent pyrexia, and salt-losing nephropathy. Culture of an early morning specimen of urine grew Myco. tuberculosis, and milary tuberculosis was diagnosed. The patient responded well to antituberculosis chemotherapy and was said to be well and in a good haemodynamic state at the end of 1973.

A summary of the main features of the seven cases is given in the Table.

\section{DISCUSSION}

Miliary tuberculosis was a not uncommon sequel of a primary infection in children before the widespread use of BCG vaccination; it was very $\AA$

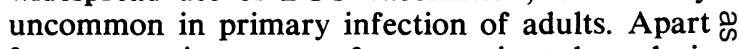
from rare instances of traumatic tuberculosis (Sumner and Nassau, 1951), bloodborne dissemination of tubercle bacilli from pre-existing $\vec{\omega}$ tuberculous lesions in adults is seen only in gross malnutrition, diabetes mellitus, and in patients on $\vec{x}$ immunosuppressive drugs. Patients with longstanding heart disease, even with a history suggestive of past tuberculosis, do not, in our $\overrightarrow{0}$ experience, show an increased incidence of tuber- -9 culosis. Miliary tuberculosis following cardiac 의 valve homotransplantation does not appear to have been reported before.

The source of infection in our series must be a matter of conjecture. Although in cases 1 and $2 \stackrel{2}{2}$ there was a history of past tuberculous infection, at necropsy no macroscopic evidence of tuber- 6 culosis was detected in our first few patients. Only two patients showed clinical or radiological evidence of miliary tuberculosis. Histological examination revealed miliary tuberculosis, which was unsuspected, except in case 3 about one week before death, and in cases 5 and 6 after a drill ${ }_{\Omega}^{\Phi}$ biopsy. Cellular miliary and confluent miliary $\overrightarrow{\vec{P}}$ tubercles without caseation or fibrosis, suggested $\frac{0}{3}$ an infection of fairly recent origin.

The strains of Myco. tuberculosis isolated from all but one of our patients were of the human type, sensitive to all antituberculosis drugs. Contamination of the homograft valves in the post-

T A B L E

SUMMARY OF THE FINDING IN SEVEN PATIENTS

\begin{tabular}{|c|c|c|c|c|c|c|c|c|c|}
\hline \multirow[b]{2}{*}{ Case } & \multirow[b]{2}{*}{ Age } & \multirow[b]{2}{*}{ Sex } & \multirow[b]{2}{*}{$\begin{array}{c}\text { Clinical } \\
\text { Diagnosis }\end{array}$} & \multirow{2}{*}{$\begin{array}{c}\text { Site of } \\
\text { Homograft } \\
\text { Insertion }\end{array}$} & \multicolumn{2}{|c|}{ Interval between } & \multirow{2}{*}{$\begin{array}{c}\text { Miliary } \\
\text { Tuberculosis } \\
\text { Diagnosed }\end{array}$} & \multirow[b]{2}{*}{$\begin{array}{c}\text { Myco. tuberculosis } \\
\text { Demonstrated }\end{array}$} & \multirow{2}{*}{$\begin{array}{c}\text { History of } \\
\text { Possible } \\
\text { Previous } \\
\text { Tuberculosis } \\
\text { Infection }\end{array}$} \\
\hline & & & & & $\begin{array}{l}\text { Operation } \\
\text { and First } \\
\text { Symptoms }\end{array}$ & $\begin{array}{c}\text { Operation } \\
\text { and Death } \\
\text { or Diagnosis }\end{array}$ & & & \\
\hline 1 & 43 & $\mathbf{F}$ & $\begin{array}{l}\text { Aortic and } \\
\text { mitral } \\
\text { incompetence }\end{array}$ & $\begin{array}{l}\text { Aorta } \\
\text { and } \\
\text { mitral valve }\end{array}$ & 3 weeks & 23 weeks & At necropsy & $\begin{array}{l}\text { From retained } \\
\text { blood } \\
\text { cultures } \\
\text { after death }\end{array}$ & $?+$ \\
\hline 2 & 65 & $\mathbf{F}$ & $\begin{array}{l}\text { Mitral } \\
\text { stenosis and }\end{array}$ & Mitral valve & 52 weeks & 53 weeks & At necropsy & Histology & + \\
\hline 3 & 59 & $\mathbf{F}$ & $\begin{array}{l}\text { Mitral } \\
\text { stenosis and }\end{array}$ & Mitral valve & 9 months & 52 weeks & At necropsy & $\begin{array}{l}\text { Culture of } \\
\text { spleen }\end{array}$ & - \\
\hline 4 & 47 & $\mathbf{F}$ & $\begin{array}{l}\text { Mitral } \\
\text { stenosis and } \\
\text { incompetence }\end{array}$ & Mitral valve & 10 weeks & 12 weeks & At necropsy & $\begin{array}{l}\text { Retained } \\
\text { blood } \\
\text { cultures }\end{array}$ & \\
\hline 5 & & & & Aorta & & & $\begin{array}{l}\text { Drill biopsy } \\
\text { of lung }\end{array}$ & & \\
\hline 6 & 64 & $\mathbf{M}$ & $\begin{array}{l}\text { Aortic } \\
\text { incompetence }\end{array}$ & Aorta & 6 weeks & 9 weeks & $\begin{array}{l}\text { Drill biopsy } \\
\text { of lung }\end{array}$ & $\begin{array}{l}\text { Biopsy } \\
\text { specimen }\end{array}$ & - \\
\hline 7 & 70 & $\mathbf{F}$ & $\begin{array}{l}\text { Floppy } \\
\text { mitral valve }\end{array}$ & Mitral valve & 10 months & 15 months & $\begin{array}{l}\text { Urine } \\
\text { culture }\end{array}$ & $\begin{array}{l}\text { Urine } \\
\text { culture }\end{array}$ & + \\
\hline
\end{tabular}


mortem room must be considered as a possible source of infection in at least some, if not in all our cases, since the majority of the homografts were obtained from coroner's necropsies and, according to Crompton (1974), 2-3 cases of active tuberculosis may be encountered in 1000 coroner's necropsies per year. While the risk of accidental contamination may not be high, nevertheless it could not be entirely excluded. It is conceivable that small numbers of tubercle bacilli carried on the homograft valves are not accessible to the immune mechanisms of the host. One can also assume a prolonged lag phase in the multiplication of the bacilli.

Considering the ages of our patients, we find that in all but one of those aged over 50 years, in whom the possibility of previous sensitization to tubercle bacilli can be assumed, the time interval between operation and the onset of symptoms was 9-12 months. This suggests either contamination with a very small number of bacilli and, as would be expected, a very prolonged lag phase, or a capacity of the immune mechanisms coping with the bacillary load for a long time until overwhelmed. In those under 50 years, again with one exception (case 4), the interval was 3-5 weeks.

It may be significant that the eight homografts used in this series were from donors aged 60 years and over, an age group likely to harbour old or recrudescent tuberculous lesions. The homografts used in cases 5 and 6 were obtained on the same day from the same mortuary. All homografts were antibiotic-sterilized, as previously described by Yacoub and Kittle (1970). Our antibiotic mixture, like that of other workers (Rittenhouse et al., 1970; Waterworth et al., 1974) did not contain antituberculosis drugs. Studies are in progress to find the most suitable addition to our formula to ensure against contamination by tubercle bacilli.

DIAGNOSIS The diagnosis of miliary tuberculosis was made by histological examination of necropsy material in four and during life in three patients. In case 3 , the diagnosis was suspected five days before death. Definite radiological evidence of miliary tuberculosis was present in cases 5 and 6 , and the diagnosis was confirmed by histological examination of drill biopsy specimens of the lungs. As far as could be ascertained, the diagnosis in our seventh case was made on a urine culture positive for Myco. tuberculosis.

Haematological investigations were inconclusive. The erythrocyte sedimentation rate, how- ever, was significantly raised in most patients. Blood cultures were negative. The blood cultures taken during the last 10 days before death and retained in the laboratory for some weeks provided material in some cases for the subsequent recovery of tubercle bacilli by culture or animal inoculation.

Late diagnosis and unawareness of the possibility of this complication no doubt account for the high mortality. Emery and Lorber (1950) stated that it may be impossible to diagnose miliary tuberculosis from lung radiographs, even where miliary tuberculosis is demonstrated at necropsy. Treip and Meyers (1959) found that $75 \%$ of cases of miliary tuberculosis were undiagnosed before necropsy, and of 12 fatal cases reported by Brunner and Haemerrli (1964), in only one patient was the diagnosis suspected before death.

While we expect to be able to control accidental contamination of our homografts by tubercle bacilli by suitable additions to the antibiotic mixture used for sterilization of the valves, any unexplained pyrexia weeks or up to one year after operation should raise the suspicion of tuberculosis and be investigated with this in view, and we suggest that full antituberculosis chemotherapy should be started even on suspicion of this diagnosis.

\section{REFERENCES}

Barnes, R. W., Rittenhouse, E. A., Mohri, H., and Merendino, K. A. (1970). A clinical experience with betapropiolactone-sterilized homologous aortic valve followed up to four years. Journal of Thoracic and Cardiovascular Surgery, 59, 785.

Barratt-Boyes, B. G. and Roche, A. H. G. (1969). A review of aortic valve homografts over a six and one-half year period. Annals of Surgery, 170, 483.

Brunner, K. and Haemmerli, U. P. (1964). Needle biopsy of the liver in the early diagnosis of miliary tuberculosis. German Medical Monthly, 9, 372. Quoted by Proudfoot et al. (1969).

Crompton, M. R. (1974). Personal communication.

Emery, J. L. and Lorber, J. (1950). Radiological and pathological correlation of miliary tuberculosis of lungs in children with special reference to choroidal tubercles. British Medical Journal, 2, 702.

Gonzalez-Lavin, L., Al-Janabi, N., and Ross, D. N. (1972). Long-term results after aortic valve replacement with preserved aortic homografts. Annals of Thoracic Surgery, 13, 594.

Grehl, T. M., Cohn, L. H., and Angell, W. W. (1972). Management of candida endocarditis. Journal of Thoracic and Cardiovascular Surgery, 63, 118. 
McKay, R. and Yacoub, M. H. (1973). Clinical and pathological findings in patients with 'floppy' valves treated surgically. Circulation, 47 and 48, Supplement 3, 63 .

Rittenhouse, E. A., Sands, M. P., Mohri, H., and Merendino K. A. (1970). Sterilization of aortic valve grafts for transplantation. Archives of Surgery, 101, 1.

Sumner, J. and Nassau, E. (1951). Trauma and tuberculosis. Tubercle, 32, 33.

Treip, C. and Meyers, D. (1959). Fatal tuberculosis in a general hospital: a diagnostic problem. Lancet, $1,164$.

Waterworth, P. M., Lockey, E., Berry, E. M., and Pearce, H. M. (1974). A critical investigation into the antibiotic sterilization of heart valve homografts. Thorax, 29, 432.

Yacoub, M. H. and Kittle, C. F. (1970). Sterilization $\overline{\bar{\sigma}}$ of valve homografts by antibiotic solutions. Cir- $\bar{D}$ culation, 41 and 42, Supplement 2, p. 29.

Yacoub, M. H., Towers, M., and Somerville, W. (1972). Results of mitral valve replacement using $\vec{O}$ unstented fresh semilunar valve homografts. Circulation, 45 and 46, Supplement 1, p.44.

Requests for reprints to: Dr. E. Nassau, Department of Pathology, Harefield Hospital, Harefield, Uxbridge, Middlesex UB9 6JH. 